\title{
COVID-19: The Regulatory and Supervisory Implications for the Banking Sector
}

\author{
A Joint IMF-World Bank Staff Position Note ${ }^{1}$
}

May 21, 2020

\section{Executive Summary:}

This note provides a set of high-level recommendations that can guide national regulatory and supervisory responses to the COVID-19 pandemic and offers an overview of measures taken across jurisdictions to date. The banking sector plays a critical role in mitigating the unprecedented macroeconomic and financial shock caused by the pandemic. Timely, targeted and well-designed regulatory and supervisory actions are essential to maintain the provision of critical financial services, particularly to households and firms that are affected most, while mitigating financial risks, maintaining balance sheet transparency, and preserving longer-term financial policy credibility. In this context, authorities should employ the embedded flexibility of regulatory, supervisory, and accounting frameworks, and encourage judicious loan restructuring while continuing to uphold minimum prudential standards. Standard-setting bodies have issued guidance to support national authorities in their efforts to provide effective, sound, and well-coordinated policy measures. Thus far, national policy measures around the world have targeted utilization of available bank capital and liquidity buffers, supporting affected borrowers, promoting balance sheet transparency, and maintaining operational and business continuity of banks as well as payment systems. However, some developing countries have fewer options at their disposal due to limited policy buffers, weaker implementation capacity, and less-sophisticated regulatory frameworks. This could explain their higher reliance on policy responses that are not consistent with the recommendations discussed in this note, which may generate new risks.

\section{Disclaimer:}

The views expressed in this Joint Staff Position Note are those of the author(s) and do not necessarily represent the views of the IMF, its Executive Board, or IMF Management, nor do they necessarily reflect the views of the World Bank, its Board of Executive Directors, or the governments they represent.

\footnotetext{
${ }^{1}$ This note has been prepared by an IMF-World Bank staff team guided by Aditya Narain and Nigel Jenkinson (IMF) and Alfonso Garcia Mora and Yira Mascaro (World Bank), and comprising: Dirk Jan Grolleman and Hee Kyong Chon, with inputs from the MCMFR team (IMF); and Pierre-Laurent Chatain, Erik Feyen, and Tatiana Alonso Gispert, with inputs from the FCI GP Stability Team (World Bank). Approved by Tobias Adrian (IMF) and Ceyla Pazarbasioglu (World Bank).
} 


\title{
COVID-19: The Regulatory and Supervisory Implications for the Banking Sector
}

\author{
A Joint IMF-World Bank Staff Position Note ${ }^{1}$
}

May 21, 2020

\section{Executive Summary:}

This note provides a set of high-level recommendations that can guide national regulatory and supervisory responses to the COVID-19 pandemic and offers an overview of measures taken across jurisdictions to date. The banking sector plays a critical role in mitigating the unprecedented macroeconomic and financial shock caused by the pandemic. Timely, targeted and well-designed regulatory and supervisory actions are essential to maintain the provision of critical financial services, particularly to households and firms that are affected most, while mitigating financial risks, maintaining balance sheet transparency, and preserving longer-term financial policy credibility. In this context, authorities should employ the embedded flexibility of regulatory, supervisory, and accounting frameworks, and encourage judicious loan restructuring while continuing to uphold minimum prudential standards. Standard-setting bodies have issued guidance to support national authorities in their efforts to provide effective, sound, and well-coordinated policy measures. Thus far, national policy measures around the world have targeted utilization of available bank capital and liquidity buffers, supporting affected borrowers, promoting balance sheet transparency, and maintaining operational and business continuity of banks as well as payment systems. However, some developing countries have fewer options at their disposal due to limited policy buffers, weaker implementation capacity, and less-sophisticated regulatory frameworks. This could explain their higher reliance on policy responses that are not consistent with the recommendations discussed in this note, which may generate new risks.

\section{Disclaimer:}

The views expressed in this Joint Staff Position Note are those of the author(s) and do not necessarily represent the views of the IMF, its Executive Board, or IMF Management, nor do they necessarily reflect the views of the World Bank, its Board of Executive Directors, or the governments they represent.

\footnotetext{
${ }^{1}$ This note has been prepared by an IMF-World Bank staff team guided by Aditya Narain and Nigel Jenkinson (IMF) and Alfonso Garcia Mora and Yira Mascaro (World Bank), and comprising: Dirk Jan Grolleman and Hee Kyong Chon, with inputs from the MCMFR team (IMF); and Pierre-Laurent Chatain, Erik Feyen, and Tatiana Alonso Gispert, with inputs from the FCl GP Stability Team (World Bank). Approved by Tobias Adrian (IMF) and Ceyla Pazarbasioglu (World Bank).
} 


\section{(I) Context and Motivation}

1. The COVID-19 pandemic has caused an unprecedented global recession with adverse consequences for unemployment and poverty. The financial sector plays a critical role in mitigating this macroeconomic shock. As liquidity challenges give way to solvency problems, defaults on debt will rise and the pressure on the banking system will grow. Overall, the global banking system is on a much stronger footing due to the implementation of the G20 financial regulatory reforms. ${ }^{2}$ Nevertheless, given the unprecedented nature of the current crisis, financial regulators and supervisors face challenges to maintain financial stability, preserve the well-functioning core markets, and ensure the flow of credit to the real economy. The challenges for some emerging markets and developing economies (EMDEs) are particularly daunting as several of them have limited buffers, supervisory capacity constraints, and pre-COVID-19 vulnerabilities in the financial sector.

2. National authorities have taken wide-ranging policy measures to support the real sector and maintain adequate liquidity in the financial system. Debt moratoria and large-scale fiscal support, including credit guarantees, have provided much-needed relief to affected sectors and borrowers (households and SMEs in particular)—although this has stretched fiscal space in some countries and may have strengthened the bank-sovereign nexus. To address severe strains in key funding markets, policy makers have resorted to liquidity and monetary stimulus. These measures have supported financial sector resilience and lending. Nevertheless, it will take time for the economic impact of COVID-19 to become fully apparent on the balance sheets of financial institutions and companies.

3. Standard-Setting Bodies (SSBs) have issued guidance to support national authorities in their efforts to provide sound and well-coordinated policy measures (see Annex 1). They have several objectives including, but not limited to: (i) supporting measures being taken by national jurisdictions to combat the pandemic, notably in the form of (carefully designed) general debt moratoria; (ii) encouraging the international financial community to make use of the flexibility existing within global standards, including buffers; (iii) providing authorities and financial institutions with additional operational capacity to respond to the immediate financial stability priorities; and (iv) enhancing transparency and consumer protection. Overall, the actions covered by SSBs aim to provide a rapid and coordinated response to support the real economy, preserve financial stability, and ensure markets continue to function.

4. This note provides the IMF and the World Bank staff's high-level recommendations and guidance on the appropriate regulatory and supervisory responses for the banking sector and offers an overview of measures taken across jurisdictions to date. Given the very challenging circumstances economies are facing, authorities need to address how to support the immediate needs of the real economy while ensuring the continued trust and confidence in the financial system and preserving financial stability. Authorities should employ the embedded flexibility of regulatory, supervisory, and accounting frameworks while continuing to uphold minimum regulatory standards. This would avoid imposing further harm on an already fragile economy, or significantly eroding financial policy credibility once the crisis has passed.

\footnotetext{
${ }^{2}$ For details, please see "Basel III: Finalizing post-crisis reforms" (https://www.bis.org/bcbs/publ/d424.htm).
} 
(II) Recommendations to Guide National Regulatory and Supervisory Responses

5. In contributing to public policy and developing their own responses, bank regulators and supervisors can build on the following high-level recommendations:

(1) Use the flexibility in the regulatory and supervisory framework while upholding minimum prudential standards and preserving consistency with international standards. Prudential buffers under the Basel III framework are designed to be used in times of stress. Authorities should emphasize that banks are able to draw down their available capital buffers to absorb losses arising from the pandemic and maintain key financial services to the real economy. ${ }^{3}$ Jurisdictions that have set the countercyclical capital buffer above zero should consider its release, as well as the relaxation of other macroprudential measures depending on the objectives of those measures and countryspecific circumstances. Supervisors should also ensure that banks temporarily limit capital distribution until the impact of the crisis becomes clear (e.g., dividend payouts, share buybacks, exceptional bonus payments) and that buffers are rebuilt over an appropriate timeframe. Liquidity buffers in domestic and foreign currency should also be used, if needed, in accordance with the Basel Liquidity Coverage Ratio (LCR) standard or other domestic liquidity requirements. Importantly, the flexibility embedded in the framework should be applied in adherence to the domestic minimum prudential requirements, internationally agreed standards and the guidelines from SSBs. This will ensure that trust and confidence in the banking system, the soundness of financial institutions, and the stability of the financial system are sustained in the medium to long term. More broadly, countries that have made progress to align their regulatory and prudential frameworks with international standards and best practice, should remain vigilant that these achievements are preserved.

(2) Facilitate, through timely prudential guidance, well-designed public and private support interventions that target affected borrowers and sectors. Jurisdictions have undertaken a wide array of measures to support businesses and individuals affected by the pandemic, such as providing government-funded loans, public guarantee schemes, and temporary payment moratoria. Simultaneously, banks are working with affected borrowers to restructure loans for firms and individuals heavily impacted by the crisis. Supervisors should encourage banks to prudently restructure loans and maintain the flow of credit to the economy. In this context, supervisors need to clearly specify how these support measures should be treated in the prudential framework.

(3) Ensure that policy responses minimize opportunities for moral hazard and maintain adherence to sound credit risk management practices while facilitating the effective allocation of new credit. It is therefore key that policy responses: (i) be time-bound; (ii) have a sunset clause and a clear exit strategy; (iii) are targeted to ensure that only viable firms benefit as much as possible; and (iv) account for potential moral hazard in their design and implementation

\footnotetext{
${ }^{3}$ Flexibility embedded in the prudential framework allows for employing a more conservative approach and building buffers in good times, while using the created policy room and buffers in bad times. This should be distinguished from regulatory forbearance (lowering minimum requirements), which risks undermining financial soundness of banks and financial stability in the medium to longer term.
} 
monitoring. Should the policy response take the form of general payment moratoria, it is essential to ensure that: (i) borrowers that were already nonperforming before the pandemic do not unduly benefit from wide-ranging repayment holidays; and (ii) borrowers are not disincentivized to resume loan repayment at the end of the moratorium. Supervisors should ensure that banks continue to carefully assess the credit quality of exposures subject to these measures in line with the guidance provided by SSBs (see Annex 1).

(4) Provide guidance on asset classification and provisioning building on the guidance from SSBs and refrain from relaxing the regulatory definition of nonperforming exposures. The unprecedented level of uncertainty surrounding the economic impact of COVID-19 poses significant challenges to reliably estimate credit losses. Banks will need to assess the impact on borrowers in the short and medium term (also considering the impact of fiscal support mechanisms on losses, provisioning, and capital). SSBs have provided guidance on the treatment of restructuring and moratoria in determining the performance of exposures and estimating credit losses (see Annex 1). ${ }^{4}$ Supervisors should build on this guidance to ensure expected losses are recognized on a timely basis while avoiding undue procyclical effects. Supervisors should also convey their expectation about how different scenarios should be considered when assessing borrowers' creditworthiness and estimating loan allowances and monitor bank behavior accordingly. Banks should regularly reassess the status of credit exposures and the level of provisioning as the situation evolves. The easing of regulatory definition of nonperforming loans, even on a temporary basis, should be avoided.

(5) Maintain transparency and provide, where necessary, additional guidance on risk disclosure. Experience with past crises shows that transparency is a precondition for maintaining trust in the system and for market discipline to work effectively, and thus limiting moral hazard. It is therefore key to disclose: (i) materiality of loan restructuring; (ii) the performance of the loan portfolio; (iii) any adjustments made to policies to assess borrowers' creditworthiness; and (iv) the impact of these adjustments. When needed, supervisors should provide additional guidance to ensure that the policies used to deal with the crisis and their impact are disclosed.

(6) Suspend the automaticity of corrective supervisory action triggers to deal with the extraordinary circumstances of the current pandemic. In some countries, a fall in the capital adequacy ratios towards or below minimum requirements may automatically trigger the activation of corrective supervisory action. Authorities could temporarily suspend (to the extent legally permissible) the automatic activation of these triggers when banks are fundamentally sound and the decline in regulatory capital ratios is expected to be temporary. This should be reviewed on a case by case basis. Further, even a temporary decline in capital ratios below minimum thresholds should be accompanied by a timely and credible capital restoration plan. Given the uncertainty and the impact of the crisis, capital restoration plans may have a longer time horizon than usually

\footnotetext{
${ }^{4}$ For instance, in line with Basel guidelines (BCBS, Guidelines on the Prudential Treatment of Problem Assets: Definition of non-performing exposure and forbearance, April 2017), if restructuring has little impact on the net present value of the exposure, the borrower is likely to perform under the renegotiated terms (or when the moratorium ends), the loan should not be considered in default or non-performing in a prudential sense.
} 
would be the case. Over time, the capital plan should be closely monitored by the supervisor to ensure that the bank is satisfactorily meeting its capital targets. Potential measures to restore liquidity levels should also be discussed and executed to prevent additional stress on the bank and on the financial system. Where the bank is unable to provide a credible restoration plan and there is a more material and longer-term impact with major systemic implications, the supervisor should work with governments as additional actions may need to be considered to support the financial system.

(7) Review supervisory priorities and maintain close dialogue with the industry. Supervisors should re-prioritize their work taking into account risks and areas most heavily impacted by the pandemic, including banks' liquidity profile, credit exposures to vulnerable sectors, and operational resilience. Supervisors should request banks to review and enhance the effectiveness of their business continuity plans (e.g., identification of critical functions, special work arrangements, maintaining the function of the Board). In addition, supervisors should consider postponing resource intensive activities (e.g., routine stress tests/full scope onsite inspections that might be less relevant in the current context and that may divert banks' management from more pressing tasks). Regulators should also consider adjusting phase-in periods of new prudential requirements in a coordinated and consistent manner.

(8) Coordinate actively with colleague supervisors, domestically and internationally, and other relevant authorities. On the domestic level, it is essential that financial sector policy responses be coordinated and communicated using existing institutional arrangements for financial stability. In addition, financial markets are global, and countries are facing similar challenges in dealing with the crisis. Working together in a coordinated fashion (either in the context of SSBs, regional cooperation arrangements, or home-host relationships for the supervision of internationally active banks and financial groups) will help inform the policy response at all levels, preserve the ability of the financial system to finance the global economy, and minimize the risks of fragmentation and contagion across countries.

(9) Ensure the smooth functioning of critical market infrastructures (e.g., securities clearing, settlement and payment systems). Central banks and supervisory authorities should closely monitor the resilience of the financial system, particularly key nodes that are critical for financial stability. Weaknesses in these nodes and their interactions could tighten financial conditions and impact the provision of financial services, the execution and transmission of monetary policy, and potentially the stability of the financial system. Central banks and supervisory authorities should also monitor the functioning of retail payment systems to maintain confidence in the system given the system-wide impact of any failure.

(III) Overview of Countries' Prudential Measures to Address the Impact of COVID-19

6. Most countries have enacted emergency measures aimed at supporting the flow of credit to the real economy while mitigating the build-up of risks through asset quality deterioration. In line with the recommendations above, these measures include: (i) prudential regulatory and 
supervisory measures to support banks facilitating the real economy (recommendations 1, 6, and 7); (ii) measures supporting borrowers and loan restructuring (recommendations 2, 3, 4, and 5); (iii) operational and business continuity measures (recommendation 7); and (iv) measures to strengthen payment systems (recommendation 7 and 9). An overview of the different measures taken by supervisory authorities is provided in Table 1 below.

7. Across all of these measures, SSBs have been active to promote international coordination and consistency in approaches (recommendation 8-see Annex 1 for details on guidance provided by SSBs). In particular, countries with limited policy capacity could benefit from international cooperation and information sharing, either through SSBs or in regional groupings, as this will help them in formulating their policy responses.

\section{Prudential regulatory and supervisory measures to support banks facilitating the real economy}

8. Authorities have taken capital, liquidity and borrower-based macroprudential measures, using the flexibility in the framework (recommendation 1). Apart from allowing banks to use regulatory buffers (capital conservation, countercyclical, systemic buffers, and other regulatory buffers introduced to mitigate system-wide vulnerabilities), which are designed to be drawn down during adverse times, ${ }^{5}$ some supervisors have provided guidance in the context of Pillar 2 on the use of buffers held above the minimum requirements and eligible capital elements. Several supervisors have imposed restrictions on dividends, share buy-backs, and bonuses for banks to ensure that the release of buffers contributes towards bolstering bank resiliency. Further, various authorities have allowed Liquidity Coverage Ratios to drop temporarily below the minimum requirement and are encourage banks to deploy their stock of high-quality liquid assets. A few have relaxed borrower-based macroprudential constraints (e.g., loan-to-value and debt-to-income ratios) to support lending. Generally, the measures taken were in line with the recommendations, but several cases were observed where regulatory relief was granted by lowering minimum requirements (e.g., lowering of risk weights for loans to small and medium enterprises (SMEs) and affected sectors like tourism and health) or making changes to regulations that deviated from internationally agreed standards, potentially undermining the credibility of these standards and contributing to market fragmentation, and eventually, solvency issues.

9. Authorities have revised their enforcement approaches and alleviated operational pressures (recommendations 6 and 7). The revisions to enforcement approaches include: (i) avoiding automatic corrective action triggers; (ii) revising strategies for early supervisory actions when capital ratios fall towards minimum requirements; and (iii) extension of corrective periods. With respect to measures to alleviate operational pressure on the industry, supervisors have extended the Basel III implementation timeline in line with the Basel Committee for Banking Supervision's (BCBS's) decision. For example, many countries have deferred the entry into force of some international standards, such as Total LossAbsorbing Capacity (TLAC), large exposures, Net Stable Funding Ratio (NSFR), certain operational risk

\footnotetext{
${ }^{5}$ These buffers, introduced in response of the global financial crisis, are proving to be an important element in the supervisory response of $\mathrm{G} 20$ countries to the challenges of the current crisis. While these buffers have been adopted broadly by advanced economies, their implementation and availability across EMDEs is more limited.
}

CInternational Monetary Fund. Not for Redistribution 
capital requirements and accounting rules (i.e., IFRS 9). In addition, some jurisdictions have extended the transition period of certain prudential requirements, and/or introduced transitional arrangements for the regulatory capital treatment of Expected Credit Losses (ECLs). Lastly, to alleviate further operational burden on banks, non-critical reporting and/or stress testing exercises have been put on hold or postponed.

\section{Measures related to supporting borrowers and loan restructuring}

10. Supervisory authorities supported public and private emergency policy measures that aim to support borrowers that have become temporarily cash-strapped and unable to make payments (recommendation 2). In several countries supervisors have provided guidance and set clear expectations on how government guaranteed loans should be taken into account in risk-based capital calculations (i.e., sovereign treatment of qualifying guarantees), how restructured loans should be treated (i.e., restructuring does not automatically result in nonperforming exposures), and how public and private moratoria need to be taken into account in prudential asset classification and provisioning (i.e., loans covered by moratoria should be treated similar to restructured loans and the guidance provided by SSBs). ${ }^{6}$

11. At the same time (contrary to recommendations 3,4 , and 5 ), several extraordinary measures have been introduced by some authorities through regulatory forbearance. These measures include, inter alia, (i) freezing the classification status of all credit exposures prior to COVID-19; (ii) extension on the number of past-due days after which a credit is considered nonperforming; and, in some extreme cases, (iii) allowing banks to postpone adequate provisioning (e.g., roll-forward expected losses) or providing blanket suspension of provisioning requirements for loans covered by moratoria. While these measures offer immediate relief, they undermine sound credit risk management practices and provisioning requirements, as such measures also mask actual losses and the true financial position of the bank. In the absence of fiscal buffers and adequately capitalized banks, such solutions might be tempting, but expose the banking system to significant risk, particularly for systems that had pre-existing vulnerabilities.

12. Generally, authorities have recognized and exerted efforts to reduce moral hazard in these public policy measures and promote transparency and risk disclosures (recommendation 3 and 5). Authorities have tried to limit moral hazard by making the measures time bound, clearly defining the sectors and loans in scope of government guarantees and moratoria and requiring additional reporting to facilitate monitoring and assessment of the impact of the measures. However, credible exit strategies (in particular for moratoria) are also critical and need more attention. ${ }^{7}$ Further, in supporting prudent restructuring, supervisors have encouraged banks to implement enhanced credit monitoring approaches and imposed specific public disclosure requirements. These transparency

\footnotetext{
${ }^{6}$ In parallel, several countries are putting in place temporary measures to reduce liquidations of cash-strapped, but otherwise viable firms and facilitate firm restructuring.

${ }^{7}$ While public moratoria could provide immediate relief to borrowers, the pros and cons compared to marketbased restructuring should be carefully considered.
} 
measures ensure that credit risk continues to be well monitored at both the micro- and macroprudential levels and that market discipline continues to play its critical role.

\section{Operational and business continuity measures}

13. Authorities have given priority to operational resilience and business continuity (recommendation 7). Precautionary lock-down measures are testing the business continuity plans of banks and supervisory authorities. Remote and split site working, and limited staff availability may challenge the execution of operations. Disruptions to telecoms or third-party service providers could also affect operations. In efforts to optimize their capacity and allow banks to focus on their key operations, supervisors have actively reprioritized their work plans, provided guidance on data security (e.g., assuring that ad-hoc measures to facilitate remote working are secure) and emphasized business continuity planning and monitoring. Both advanced economies (AEs) and emerging markets and developing economies (EMDEs) have prompted financial institutions to shift towards digital channels to enable contactless customer engagement during periods of quarantine and social distancing and to accelerate the path towards digitized core-banking processes such as electronic know your customer (e-KYC), digital signature collection, and online document submission. In general, banks business continuity planning and the regulatory requirements appear to be effective, as no systemic disruptions in bank operations have occurred.

\section{Measures strengthening payment systems}

14. Central banks and securities market regulators have adopted measures to support payment systems (recommendation 7 and 9). Financial market infrastructures contribute to the mitigation of risks arising from transactions between financial institutions, but they also concentrate risks and must abide by strict risk management and containment measures, made more stringent after the $2008^{8}$ crisis but which could, especially in EMDEs, be put to the test by the current pandemic. As a response to the COVID-19 crisis, central banks and securities market regulators have requested that financial market infrastructures (FMIs) review their business continuity plans (BCP), crisis management procedures, and critical dependencies to financial and nonfinancial providers. Some central banks have gone further and invoked their BCP for the critical systems they operate to contain the risks of unavailability of critical staff, inability to access physical premises, increasing cyber-attacks on work-from-home settings, and volatility in financial markets. Beyond operational risk, the pandemic might have an impact for FMls on business risk in a scenario of potential lower revenues either due to regulatory mandate to reduce fees, lower business volume or impairment of specific business lines, and on the management of financial risks in a context of global crisis and volatility in global and domestic financial markets.

\footnotetext{
${ }^{8}$ CPMI-IOSCO Principles for Financial Market Infrastructures replaced in 2012 the 2001 Core Principles for Systemically Important Payment Systems.
} 
Table 1: Prudential Recommendations and Policy Measures in Response to the COVID-19 Pandemic

\begin{tabular}{|c|c|}
\hline Recommendations & Substance covered \\
\hline $\begin{array}{l}\text { 1. Use embedded flexibility and } \\
\text { uphold minimum standards }\end{array}$ & $\begin{array}{l}\text { - Maintain minimum capital requirements. } \\
\text { - Maintain consistency with international standards. } \\
\text { - Follow guidance provided by SSBs. } \\
\text { - Allow the use of capital buffers (e.g., conservation, countercyclical). } \\
\text { - Release countercyclical capital buffers. } \\
\text { - Ease other macroprudential measures (e.g., loan-to-value (LTV) and } \\
\text { debt-to-income (DTI) ratios). } \\
\text { - Limit dividend distributions and share buy-backs. } \\
\text { - Allow the use of liquidity buffers (i.e., LCR, NSFR). }\end{array}$ \\
\hline $\begin{array}{l}\text { 2. Facilitate public and private } \\
\text { support measures }\end{array}$ & $\begin{array}{l}\text { - Support/facilitate the restructuring of loans. } \\
\text { - Lower risk weights for credits with government guarantees. } \\
\text { - Provide guidance on the treatment of moratoria. }\end{array}$ \\
\hline 3. Limit moral hazard & $\begin{array}{l}\text { - Implement timebound policy measures. } \\
\text { - Implement clearly scoped policy measures. } \\
\text { - Supervise and monitor the implementation of policy measures. }\end{array}$ \\
\hline $\begin{array}{l}\text { 4. Provide guidance on asset } \\
\text { classification and provisioning }\end{array}$ & $\begin{array}{l}\text { - Revise automatic reclassification triggers for restructured loans. } \\
\text { - Provide guidance on the application of provisioning requirements. } \\
\text { - Provide guidance on the application of asset classification } \\
\text { requirements. }\end{array}$ \\
\hline 5. Maintain transparency & $\begin{array}{l}\text { - Communicate policy responses transparently to the market. } \\
\text { - Enhance and provide guidance on risk disclosures to incorporate: } \\
\text { - changes to underwriting, credit risk and provisioning policies, } \\
\text { and materiality and impact of such changes. } \\
\text { - performance of the loan portfolio materiality of restructured } \\
\text { loans and moratoria. }\end{array}$ \\
\hline $\begin{array}{l}\text { 6. Suspend the automaticity of } \\
\text { supervisory action triggers }\end{array}$ & $\begin{array}{l}\text { - Suspend automaticity of corrective action triggers. } \\
\text { - Revise early supervisory action strategies. } \\
\text { - Allow for longer corrective action periods. }\end{array}$ \\
\hline 7. Review supervisory priorities & $\begin{array}{l}\text { - Maintain close dialogue with the industry. } \\
\text { - Prioritize critical supervisory actions. } \\
\text { - Focus on key risks (e.g., asset quality, operational resilience). } \\
\text { - Suspend new policy initiatives. } \\
\text { - Postpone the implementation of new regulations and routine stress } \\
\text { tests. } \\
\text { - Extend transition periods for regulations in process of implementation. } \\
\text { - Reduce non-essential examinations and reporting. }\end{array}$ \\
\hline 8. Coordinate with colleagues & $\begin{array}{l}\text { - Coordinate policy responses with the government, domestic } \\
\text { supervisors, and regional supervisors. } \\
\text { - Coordinate and maintain close contact with home-host supervisors. } \\
\text { - Engage and exchange information with SSBs. }\end{array}$ \\
\hline $\begin{array}{l}\text { 9. Ensure the functioning of } \\
\text { financial markets infrastructure }\end{array}$ & $\begin{array}{l}\text { - Monitor and design policy action to maintain the resilience of: } \\
\text { - } \quad \text { securities clearing. } \\
\text { - } \quad \text { payment and settlement systems. }\end{array}$ \\
\hline
\end{tabular}




\section{Annex 1: Overview of Statements and Guidance Provided by Standard-Setting Bodies in Response to the COVID-19 Pandemic}

\begin{tabular}{|c|c|}
\hline $\begin{array}{l}\text { Standard } \\
\text { Setter }\end{array}$ & Statements and guidance \\
\hline BCBS & $\begin{array}{l}\text { The Basel Committee on Banking Supervision (BCBS) published a report on the measures to reflect } \\
\text { the impact of COVID-19, which sets out technical guidance related to the treatment of government } \\
\text { support measures and expected credit loss (ECL) accounting (April 2020). } \\
\text { https://www.bis.org/bcbs/publ/d498.pdf } \\
\text { The BCBS coordinated policy and supervisory response to COVID-19 (March 2020). } \\
\text { https://www.bis.org/press/p200320.htm } \\
\text { Governors and Heads of Supervision (GHOS) announced deferral of Basel III implementation to } \\
\text { increase operational capacity of banks and supervisors to respond to COVID-19 (March 2020). } \\
\text { https://www.bis.org/press/p200327.htm }\end{array}$ \\
\hline FSB & $\begin{array}{l}\text { The Financial Stability Board (FSB) published a report on international cooperation and coordination } \\
\text { to address the financial stability implications of COVID-19 and policy measures taken (April 2020). } \\
\text { https://www.fsb.org/2020/04/covid-19-pandemic-financial-stability-implications-and-policy- } \\
\text { measures-taken/ } \\
\text { https://www.fsb.org/work-of-the-fsb/addressing-financial-stability-risks-of-covid-19/ }\end{array}$ \\
\hline IFRS & $\begin{array}{l}\text { The International Financial Reporting Standards (IFRS) Foundation published IFRS and COVID-19 to } \\
\text { provide guidance on how the pandemic affects accounting for ECL, which highlighted that IFRS9 does } \\
\text { not provide a mechanistic approach (March 2020). } \\
\text { https://cdn.ifrs.org/-/media/feature/supporting-implementation/ifrs-9/ifrs-9-ecl-and- } \\
\text { coronavirus.pdf?la=en }\end{array}$ \\
\hline ICRR & $\begin{array}{l}\text { The International Committee for Credit Reporting (ICCR) issued a report on the treatment of credit } \\
\text { data in credit information systems in the context of the COVID-19 pandemic aimed at safeguarding } \\
\text { the integrity of credit reporting systems and protecting borrowers during the crisis (April 2020). } \\
\text { https://www.worldbank.org/en/topic/financialsector/brief/international-committee-on-credit- } \\
\text { reporting }\end{array}$ \\
\hline FATF & $\begin{array}{l}\text { The Financial Action Task Force (FATF) issued a statement on COVID-19 and measures to combat } \\
\text { illicit financing, and encouraged the use of the flexibility built into the FATF's risk-based approach to } \\
\text { address COVID-19 related challenges (e.g., through digital onboarding and simplified due diligence) } \\
\text { (April, 2020). } \\
\text { https://www.fatf-gafi.org/publications/fatfgeneral/documents/statement-covid-19.html }\end{array}$ \\
\hline IOSCO & $\begin{array}{l}\text { The International Organization of Securities Commissions (IOSCO) issued a statement noting its } \\
\text { commitment to ensure that capital markets continue to function in spite of the COVID-19 outbreak } \\
\text { to enable all participants to price and transfer risk across all traded asset classes (April 2020). } \\
\text { https://www.iosco.org/news/pdf/IOSCONEWS559.pdf }\end{array}$ \\
\hline IAIS & $\begin{array}{l}\text { The International Association of Insurance Supervisors (IAIS) released a statement to describe the } \\
\text { steps to address impact of COVID-19 on the insurance sector (March 2020). } \\
\text { https://www.iaisweb.org/page/news/press-releases//file/89387/27-march-2020-media-release-iais- } \\
\text { executive-committee-takes-steps-to-address-impact-of-covid-19-on-the-insurance-sector }\end{array}$ \\
\hline
\end{tabular}

